\title{
Effect of Sandblasting on the Bond Strength between CAD-CAM Milled Metal Post and Direct Metal Laser-sintered Metal Post: A Comparative In Vitro Study
}

Priyanka Rai ${ }^{1}$, Bharat Raj $\mathrm{R}^{2}$, Surendra Kumar $\mathrm{GP}^{3}$

\begin{abstract}
Aim: To assess and compare the bond strength of $\mathrm{Co}-\mathrm{Cr}$ metal posts fabricated with 2 different techniques: computer-aided design and computer-aided machining (CAD-CAM) and direct metal laser-sintering (DMLS).

Materials and methods: Sixty extracted noncarious, human maxillary central incisor teeth with a similar morphology were decoronated $2 \mathrm{~mm}$ coronal to the cementoenamel junction (CEJ) and the roots were endodontically treated. Post space was prepared leaving $5 \mathrm{~mm}$ of gutta percha within the root canal. Co-Cr metal posts were fabricated according to CAD-CAM and direct metal laser-sintering (DMLS) techniques and were randomly divided into four study groups: group I, CAD-CAM milled metal post without sandblasting; group II, DMLS metal posts without sandblasting; group III, CAD-CAM milled metal post with sandblasting; and group IV, DMLS metal posts with sandblasting. After sandblasting posts were cemented with glass ionomer cement, pull-out bond strength test was performed using a universal testing machine. Using Kruskal-Wallis with post hoc (Mann-Whitney) tests statistical analysis of data was performed.

Result: The highest pull-out bond strength was reported in group-IV (mean value $=6.65 \pm 3.10 \mathrm{MPa}$ ). And the lowest was recorded for group-I (mean value $=4.38 \pm 2.69 \mathrm{MPa}$ ). No significant difference in pull-out bond strength was found among the different groups $(p>0.05)$ due to smaller sample size.

Conclusion: Within the limitations of this study, results suggest that surface treatment with sandblasting with $50 \mu$ m aluminum oxide particles was found to be an effective method for improving the bond between the DMLS and CAD-CAM milled metal posts.

Keywords: Bond strength, Computer-aided design and computer-aided machining, Direct metal laser-sintering.

International Journal of Prosthodontics and Restorative Dentistry (2019): 10.5005/jp-journals-10019-1232
\end{abstract}

\section{INTRODUCTION}

In an endodontically treated tooth, when a restoration fulfilling the tooth's masticatory and esthetic function is not possible using the coronal tissue, post-core restoration is recommended. ${ }^{1}$ It has been demonstrated that posts do not strengthen the tooth. But they primarily improve the retention between the artificial crown and the remaining radicular tooth structure along with the dissipation of masticatory stresses parallel to the long axis of the tooth. ${ }^{2,3}$ Custom cast post and core are commonly used to restore these endodontically treated teeth and are considered as the standard for many years and is still used by the clinicians. ' Metal post has an advantage over the other posts in restoring the teeth as they bend less on lateral forces preventing the debonding at the core-dentin interface. Thus, reducing the chances of microleakage. ${ }^{4}$ Due to the various excellent properties of $\mathrm{Co}-\mathrm{Cr}$ alloy such as mechanical strength, corrosion resistance, low cost and biocompatibility, they have a long history of use in prosthodontics, including post and core. ${ }^{5,6}$ However, as a result of their superior melting range and potential for oxidation, base metal alloys are difficult to cast and certain inaccuracies may be incorporated in them. ${ }^{6}$ With the evolution of digital technologies such as intra-oral scanners, computer-aided design (CAD) and computer-aided machining (CAM) and rapid prototyping have eliminated manufacturing and human errors resulting in an improved accuracy of the fitting of the restorations in contrast to the conventional casting procedures. On the other hand direct metal laser-sintering (DMLS) is based on the additive metal fabrication technique using a high power laser. Molten metal powder is built up layer by layer to a 10-30 $\mu \mathrm{m}$
${ }^{1-3}$ Department of Prosthodontics, Crown and Bridge, Vokkaligara Sangha Dental College and Hospital, Vishweshwarapura, Bengaluru, Karnataka, India

Corresponding Author: Priyanka Rai, Department of Prosthodontics, Crown and Bridge, Vokkaligara Sangha Dental College and Hospital, Vishweshwarapura, Bengaluru, Karnataka, India, Phone: +91 9986727628, e-mail: priyankarai.pr32@gmail.com

How to cite this article: Rai P, Raj RB, et al. Effect of Sandblasting on the Bond Strength between CAD-CAM Milled Metal Post and Direct Metal Laser-sintered Metal Post: A Comparative In Vitro Study. Int J Prosthodont Restor Dent 2019;9(2):56-62.

Source of support: Nil

Conflict of interest: None

thickness to achieve the desired product. ${ }^{1,6}$ Retention of the post depends upon the close contact between the root canal wall and the post and on the efficiency of the cement to bond with the canal walls. ${ }^{8}$ Debonding of the posts has been reported to be the most common cause of their failure. Therefore, bond strength is clinically very important. ${ }^{7}$ The variables that affect retention of various post systems include length, diameter and design of the post, canal shape, canal preparation, luting medium, method of cementation, surface treatment and location of dental arches. ${ }^{9,10}$ Sandblasting the post is the most common micromechanical surface pretreatment modality. It has an erosive effect which naturally roughens the surface, so that the surface area and energy of the posts significantly increases. ${ }^{6,11}$ It permits the penetration and the flow of luting

o The Author(s). 2019 Open Access This article is distributed under the terms of the Creative Commons Attribution 4.0 International License (https://creativecommons. org/licenses/by-nc/4.0/), which permits unrestricted use, distribution, and non-commercial reproduction in any medium, provided you give appropriate credit to the original author(s) and the source, provide a link to the Creative Commons license, and indicate if changes were made. The Creative Commons Public Domain Dedication waiver (http://creativecommons.org/publicdomain/zero/1.0/) applies to the data made available in this article, unless otherwise stated. 
agents into the micromechanical retention thereby, reducing sole dependence of the cement for its retention. ${ }^{8}$ Various authors have reported mechanical characteristics and adaptation of metal crowns fabricated using these techniques. ${ }^{5}$ A recent study focused on the fracture resistance of teeth restored with metal posts fabricated by selective laser-melting and CAD-CAM technologies. ${ }^{1}$

But limited information is available on the bond strength of the surface-treated metal posts fabricated with these advanced techniques.

Thus, there is a need for this study to assess and compare the bond strength of sandblasted CAD-CAM milled and direct metal laser-sintered (DMLS) metal posts.

\section{Materials and Methods}

The present in vitro study was conducted in the Department of Prosthodontics Crown and Bridge, Vokkaligara Sangha Dental College and Hospital, Bengaluru, Karnataka, in association with CAD software Exocad Dental Lab, Surat, Gujarat, and Indian Institute of Science (IISC), Bengaluru. This study was approved by the ethical committee of Rajiv Gandhi University of Health Sciences, Bengaluru.

\section{Preparation of the Samples for the Study}

Sixty extracted noncarious, human maxillary central incisor teeth with a similar morphology were selected, cleaned and stored in $10 \%$ buffered formalin (VIP, Mumbai, India). Teeth were decoronated $2 \mathrm{~mm}$ coronal to the cementoenamel junction (CEJ) perpendicular to the longitudinal axis using a slow speed diamond disc (Mani, Utsunomiya, Tochigi, Japan) under water coolant (Fig. 1). They were cut in a uniform length of $13 \mathrm{~mm}$ from the apical end to standardize the remaining root length.

\section{Criteria for Teeth Selection}

After separating the crown and the root, buccolingual and mesiodistal dimensions of the roots were measured with a digital caliper (Mitutoyo, Kawasaki, Japan) for the standardization and were included for the study: (1) Diameter at cementoenamel junction (CEJ): teeth with $6.3 \pm 0.5 \mathrm{~mm}$ buccolingual diameter and $6.4 \pm 0.4 \mathrm{~mm}$ mesiodistal diameter; (2) Diameter $4 \mathrm{~mm}$ from the apex of cementoenamel junction (CEJ): teeth with $3.8 \pm 0.4 \mathrm{~mm}$ buccolingual diameter and $4.3 \pm 0.4 \mathrm{~mm}$ in mesiodistal diameter.

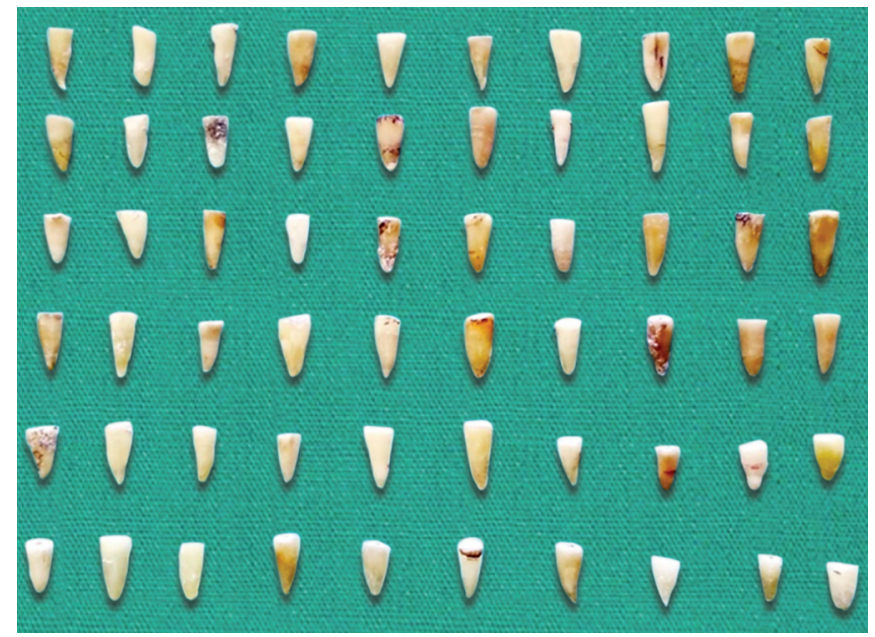

Fig. 1: Decoronated teeth (2 $\mathrm{mm}$ coronal to cementoenamel junction)

\section{Endodontic Procedure}

Step-up technique was used to instrument the root canals by using K-files (Mani, Utsunomiya, Tochigi, Japan) followed by irrigation with $1 \mathrm{~mL}$ of $5.25 \% \mathrm{NaOCl}$ (VIP, Mumbai, India) preceding the use of each instrument. Obturation was done with gutta-percha cones (Sure-endo, Seongnam-si, South Korea) following lateralcondensation technique using a eugenol-based sealer (VIP, Mumbai, India).

\section{Preparation of Post Space}

Eight millimeters of root canal filling material was removed with Peeso reamers (Mani, Utsunomiya, Tochigi, Japan) at a low speed leaving $5 \mathrm{~mm}$ of Gutta Percha (Sure-endo, Seongnam-si, South Korea) within the root canal (Fig. 2).

\section{Impression Making of Post Space}

A self-cure acrylic resin stick (DPI, Mumbai, India) was inserted inside the root canal and was made assured that it was loosely fitting and extended till the full depth of the post space. The acrylic resin stick was then coated with tray adhesive (Dentsply Aquasil, New York, Pennsylvania, United States). Light viscosity polyvinyl siloxane based impression material (Dentsply Aquasil, New York, Pennsylvania, United States) was mixed and applied inside the root canal. Lentulospiral was used to carry the impression material into the apical portion of the post space at a slow speed. The acrylic resin stick was reinforced to the full depth of post space and the impression was made.

\section{Metal Post Fabrication}

The impressions of the post space obtained were scanned with a digital scanner (Shining 3D 200+, Zhejiang, China) to transfer the $3 \mathrm{D}$ images to digital design. A computer was used to design the post space and the post within the post space using CAD software (Exocad Software, Darmstadt, Germany) (Fig. 3). The digital design obtained was used to complete standard template library (STL) files. These STL files were used to fabricate metal posts using DMLS system (EOS M 290 machine, Munich, Germany). Co-Cr alloy powder (Co: 61.8-65.8 wt\%, Cr: 23.7-25.7 wt\%, Mo: 4.6-5.6 wt\%, W: 4.9-5.9 wt\%, Si: 0.8-1.2 wt\%, Fe: $\max 0.50$ wt\%, Mn: $\max 0.10$ wt\%) was used for sintering. Similarly, metal posts (Fig. 4) were obtained after milling nickel and beryllium free $\mathrm{Co}-\mathrm{Cr}$ blocks in

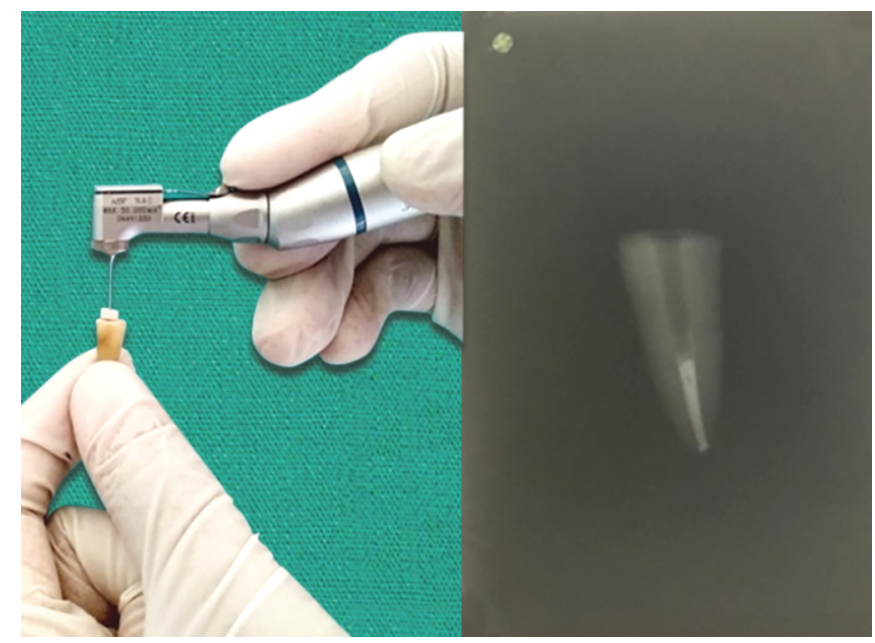

Fig. 2: Post space preparation using Peeso reamer ( $5 \mathrm{~mm}$ of apical gutta percha left intact) 


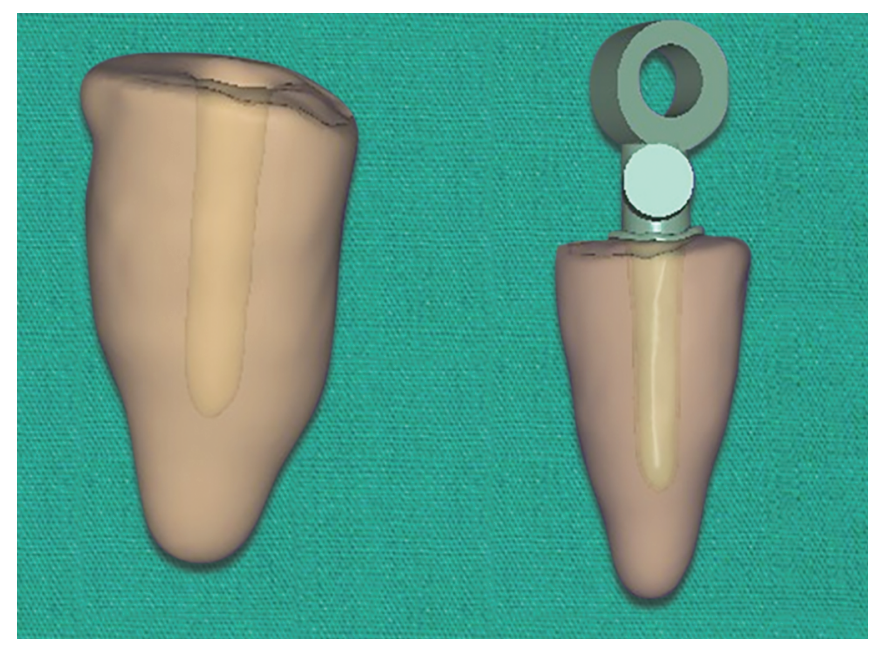

Fig. 3: Digital post space and post within the tooth

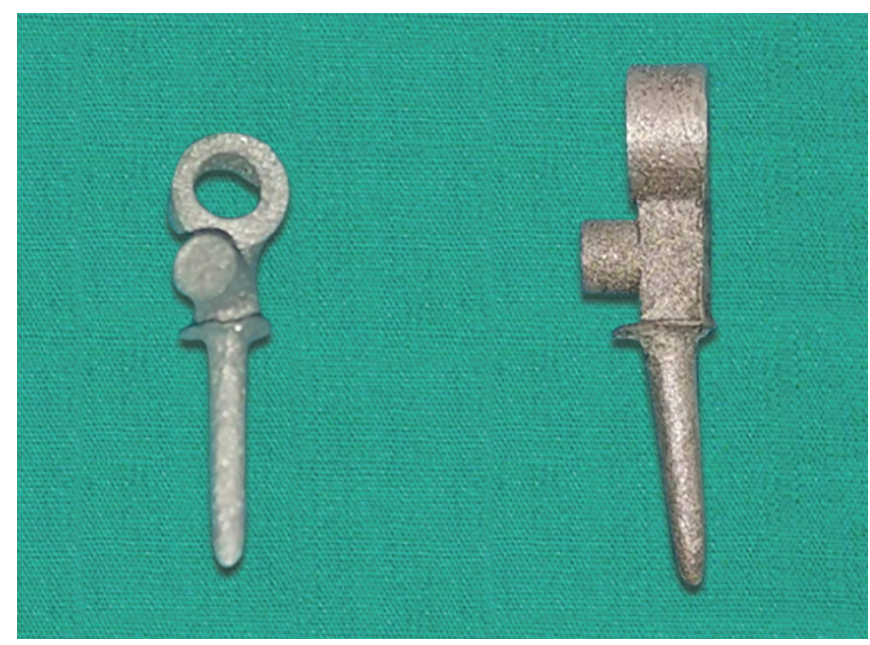

Fig. 5: Milled metal post

a milling (DC5 by ZUBLER, GA, USA) machine (Fig. 5). Specimens were randomly divided into 4 study groups wherein the control groups were not sandblasted and the experimental groups were sandblasted.

\section{Surface Treatment of Metal Posts by Sandblasting}

Sandblasting of the metal post was done with a sandblaster (Shofu Pen Blaster II, California, USA) using alumina particles $(50 \mu \mathrm{m})$ (Indiamart, Kozhikode, India) for 10 seconds at a working distance of $5 \mathrm{~mm}$ (Fig. 6). Morphological changes on the surface of metal posts were observed at a magnification of $1.5 \times$ before and after sandblasting by mounting them onto the stereomicroscope (Olympus, Shinjuku, Tokyo, Japan (Fig. 7).

\section{Orientation of the Metal Posts}

A horizontal extension was fabricated on the metal posts and a marking was made on the buccal surface of the root for the easy orientation of the post within the root canal (Fig. 8). A retention ring of $5 \mathrm{~mm}$ diameter was also constructed for attaching the stainless steel wire for the pull-out bond strength test. Retentive indentations were made on the mesial and distal sides of the

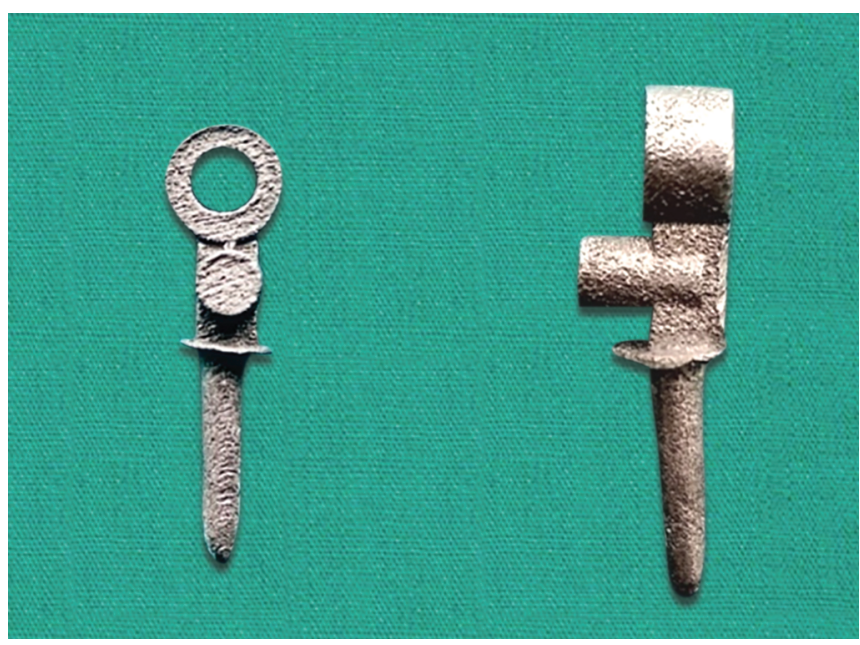

Fig. 4: DMLS metal post

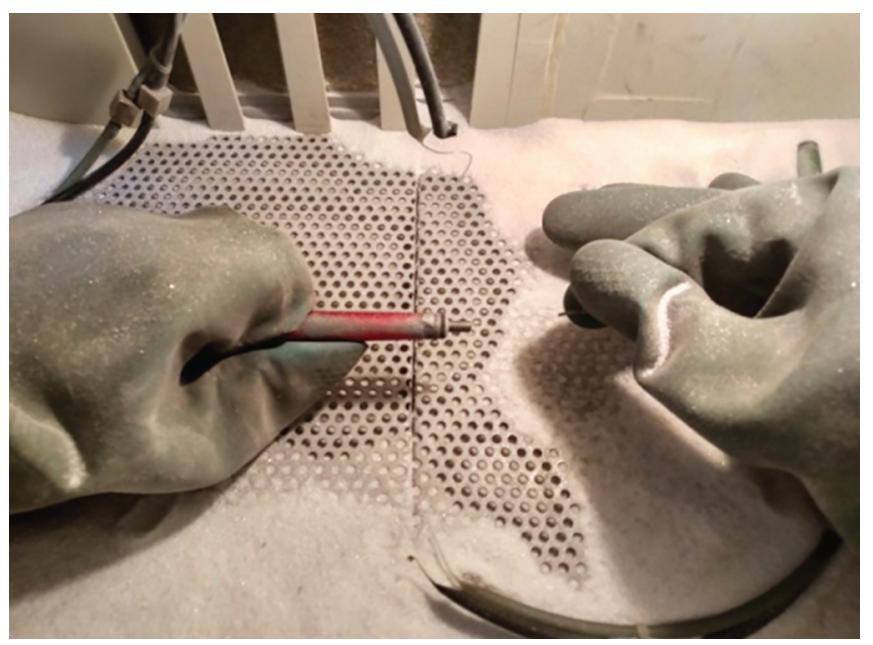

Fig. 6: Sandblasting of metal post

roots for the mechanical interlocking of the tooth with the acrylic resin.

\section{Luting of Post in the Root Canal}

Metal posts were cemented 24 hours after obturation. According to the manufacturer's instructions, the glass ionomer luting cement (Fuji; GC, Illinois, USA) was mixed and was applied onto the post and into the canal space with the spreader (Mani, Utsunomiya, Tochigi, Japan). The post was rotated slightly upon insertion to avoid trapping air, and gentle finger pressure was applied to the post in the vertical direction until the post was fully seated. The excess cement was then removed from the margins using an explorer (GDC, Hoshiarpur, Punjab, India) immediately after inserting the post in the space.

\section{Mounting of Specimens}

Putty molds were fabricated and filled with autopolymerizing acrylic resin (DPI, Mumbai, India) and the specimens were mounted in the center of the mold parallel to the long axis of its post (Fig. 9). The luting cement along with the acrylic resin blocks were allowed to set for 24 hours and then they were prepared for pull-out bond strength evaluation test. 


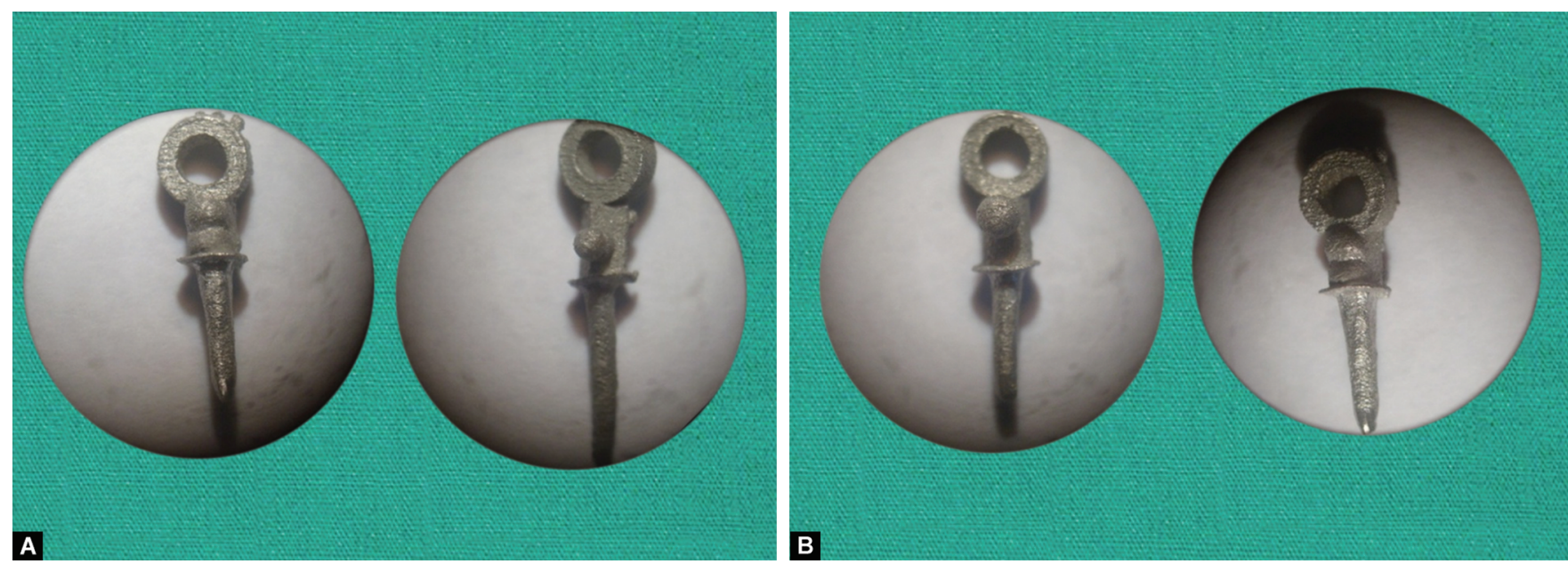

Figs 7A and B: (A) Microscopic images of CAD-CAM milled metal posts (magnification = 1.5X); (B) Microscopic images of DMLS metal posts (magnification $=1.5 \times)$

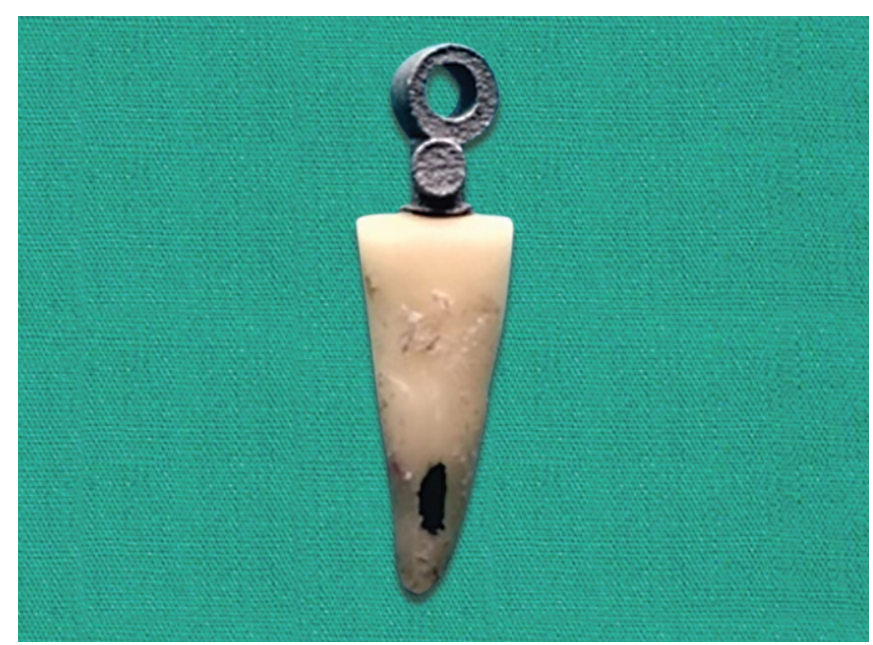

Fig. 8: Horizontal extension of the post and marking on the tooth for the orientation

\section{Pull-out Bond Strength Evaluation}

A stainless steel wire $(0.7 \mathrm{~mm})$ was tied in the ring for pull out bond strength test (Fig. 10). Then resin blocks were secured in a Universal testing machine (Mecmesin Multi-Test 10-I, Slinfold, UK). A tensile force was applied to dislodge the posts by using pneumatic grips by grasping the metal wire tied in the retention ring of the post and thus, pulling the post along its long axis (Fig. 11). A constant loading rate of $1 \mathrm{~mm} /$ minute was applied until cement failure occurred. The peak force was recorded at the point of extrusion of the post from the tooth root which was considered as the point of bond failure (Fig. 12). Force was recorded in Newton (N).

Statistical analysis was done using SPSS (Statistical Package for Social Sciences) version 20 (IBM SPASS Statistics (IBM corp. released 2011)). Descriptive statistics like mean and standard deviation were calculated. Inferential statistics like Kruskal Wallis with post hoc (Mann-Whitney) was used to compute the difference in bond strength among the groups.
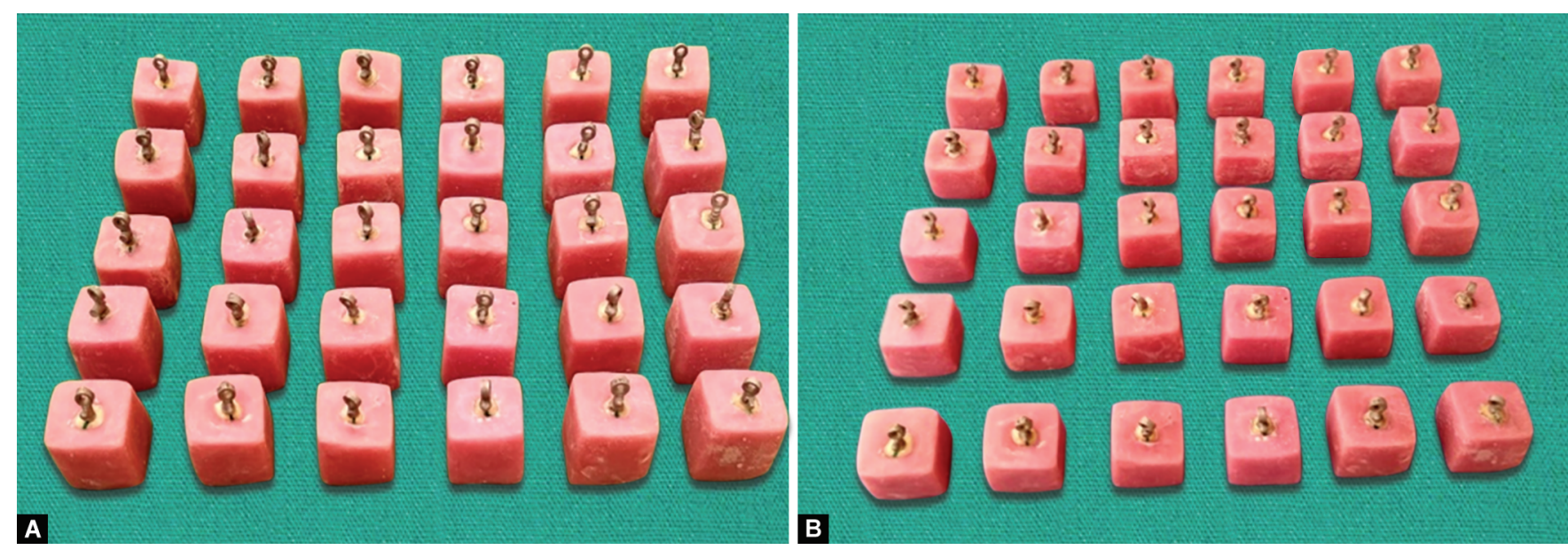

Figs 9A and B: Mounted specimen in autopolymerizing acrylic resin blocks: (A) CAD-CAM group; (B) DMLS group 


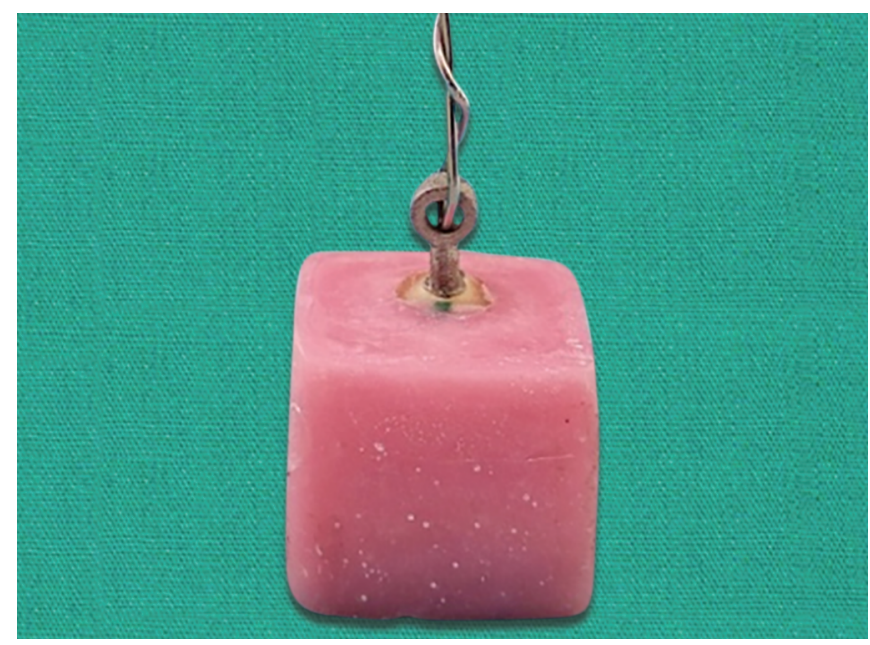

Fig. 10: Stainless steel wire $(0.7 \mathrm{~mm})$ tied in the ring for pull-out bond strength test

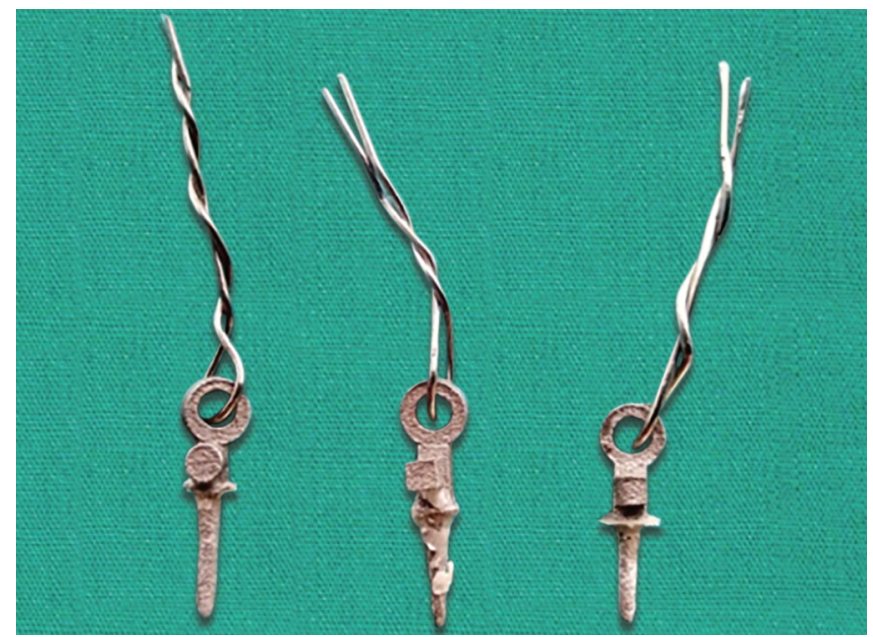

Fig. 12: Metal posts after the pull-out test

\section{Results}

Mean bond strength (MPa) between CAD-CAM milled metal posts and direct metal-laser sintered (DMLS) metal posts using Mann-Whitney test were compared and tabulated in Table 1. According to the data, highest mean pull-out bond strength was seen in group-IV $(6.65 \pm 3.10 \mathrm{MPa})$ and group-I showed the lowest values $(4.38 \pm 2.69 \mathrm{MPa})$. Table 2 illustrates the comparison of all the groups using Kruskal-Wallis test. Kruskal-Wallis test was applied to find out the statistical difference among the groups. The results thus obtained showed no statistical difference among the groups ( $p$ value $=0.203$ ). Pair wise comparison of all the groups using post hoc (Mann-Whitney test) is illustrated in Table 3. The results of pairwise comparison of bond strength using post hoc

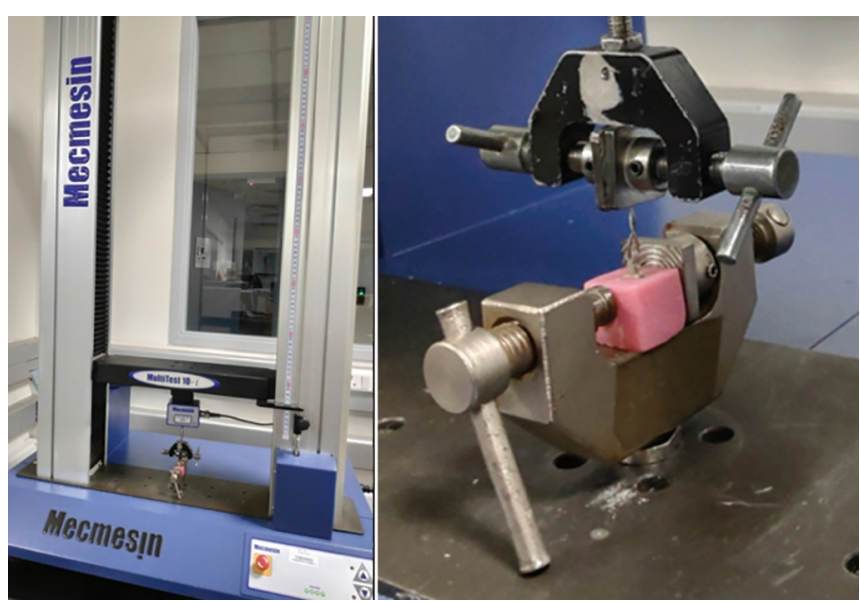

Fig. 11: Application of tensile force by pulling the metal wire to dislodge the metal post after securing the acrylic blocks in the Universal testing machine

Mann-Whitney test were statistically insignificant amongst all the groups. Therefore, the null hypothesis was accepted.

\section{Discussion}

The novel techniques such as computer aided design (CAD) and computer aided machining (CAM) as well as more recently introduced direct metal-laser sintering (DMLS) technologies have facilitated their use in daily routine and are now regarded as reliable alternatives to the conventional casting procedures. ${ }^{1}$ In dentistry, to restore an endodontically treated tooth, intraradicular posts are required to advocate the retention between the remaining radicular tooth structure and the artificial crown. ${ }^{13}$ When it comes to the reference between the prefabricated and custom posts, the custom posts are always preferred as they have supremacy over the prefabricated posts. ${ }^{14}$ There are less chances of perforation as less instrumentation is needed in the custom post. On the other hand, the prefabricated post system requires the root canals to be shaped to receive a post. ${ }^{11,18}$

In this study, the mean bond strength of the metal posts of both the groups CAD-CAM milled and DMLS metal posts were more after sandblasting as compared to the control group. This can be explained by the fact that the surfaces of these metal posts which were not sandblasted were smoother and they were not altered by any treatment. Various studies have shown that airborne particle abrasion procedures lead to larger surface area, as the surface gets activated for the bonding due to increased surface roughness and thus creating a mechanical interlocking with the luting cement. ${ }^{15-17,24}$ In this study, the pertinent finding that was reported was the bond strength of the metal posts cemented with glass ionomer cement was significantly augmented after sandblasting. This can be described by saying that along with the surface morphology, the chemical composition of the

Table 1: Comparison of bond strength using Mann-Whitney test

\begin{tabular}{lllccc}
\hline Parameter & Group & Minimum $(\mathrm{MPa})$ & Maximum $(\mathrm{MPa})$ & $\mathrm{Mean}(\mathrm{MPa})$ & $\mathrm{SD}(\mathrm{MPa})$ \\
\hline Bond strength without & CAD-CAM & 1.29 & 8.96 & 4.38 & 2.69 \\
sandblasting & DMLS & 1.80 & 10.01 & 5.36 & 2.45 \\
Bond strength with sandblasting & CAD-CAM & 1.33 & 11.50 & 6.04 & 2.83 \\
& DMLS & 1.66 & 11.46 & 6.65 & 3.10 \\
\hline
\end{tabular}


Table 2: Comparison of all the groups using Kruskal-Wallis test

\begin{tabular}{ll}
\hline Kruskal-Wallis & 4.612 \\
$p$ value & 0.203 \\
\hline
\end{tabular}

Table 3: Post hoc test (Mann-Whitney)

\begin{tabular}{ll}
\hline & $p$ value \\
\hline Group I $\times$ group II & 0.19 \\
Group I $\times$ group III & 0.22 \\
Group I $\times$ group IV & 0.04 \\
Group II $\times$ group III & 0.52 \\
Group II $\times$ group IV & 0.27 \\
Group III $\times$ group IV & 0.63 \\
\hline
\end{tabular}

$p$ value considered significant at $0.05 / 4=0.0125$

materials was also different. Both these factors will affect the bond strength. Not only the chemistry, but also the other properties of cement such as the wettability of the cement to alloy surface, the viscosity of the cement and its surface tension affects the bond strength of the metal post cemented to the tooth. ${ }^{12,19,20}$ The luting cement used in this study was conventional glass ionomer cement. Conventional glass ionomer cement has a property of bonding to dentin by the micromechanical mechanism and bond chemically to the tooth. ${ }^{21}$ Various studies have revealed better properties of glass ionomer cement as compared to the other luting cements. Glass ionomer cement has a more desirable viscoelastic property and bonding improves as the setting time increases with time. Use of resin cement results in the development of stresses due to polymerization shrinkage as an increased thickness of cement is used. Thus, the polymerization shrinkage leads to an incomplete dentin bonding as the cement from dentinal surface is dislocated. 2,22,23 Ebrahimi Dastgurdi et al. stated that glass ionomer cement is superior to zinc phosphate cement on fatigue testing. It has the ability to adhere not only to the tooth but also to the metal substructure.

In the present study, finger pressure was used while seating the post to simulate the real clinical practice. In a previous study, it was shown that seating force did not significantly alter the cement layers. ${ }^{25}$ Pull-out test was used to evaluate the bond strength luted metal posts in this study. The methodology of the pull-out bond strength test used in this study is very much different from that in push-out bond strength test. In the push-out method, after sectioning the tooth into thin slices, the slice is pushed out. The nature of push-out test is compressive whereas in pull-out bond strength test, the force is tensile.

The limitations of this study were:

- The results obtained were not statistically significant as a smaller sample size was taken.

- Long-term clinical and intraoral conditions were not simulated.

- Testing was done 24 hours after cementation of the metal posts.

- Prior thermocycling or dynamic loading was not performed.

Therefore, in order to obtain a statistically significant result, the size of the sample taken should have been larger. Moreover, further studies should be performed on the metal posts fabricated with the novel techniques after dynamic loading and thermocycling prior to tensile loading in order to closely mimic clinical and intraoral conditions.

\section{Conclusion}

Within the limitations of the study following conclusions were drawn:

- Sandblasting with $50 \mu \mathrm{m}$ aluminum oxide particles were found to be an effective method for improving the bonding between the CAD-CAM milled and direct metal laser-sintered metal posts cemented with conventional glass ionomer cement (GIC).

- Co-Cr metal posts fabricated using DMLS technology had greater pull-out bond strength after sandblasting. But CADCAM milled metal posts also showed comparable results.

- The CAD-CAM and DMLS techniques are a promising alternative to conventional casting for metal post fabrication.

\section{ACKnOWLedgment}

Sincere thanks to Indian Institute of Sciences (IISC), Bengaluru and Exocad Lab, Surat.

\section{References}

1. Bilgin MS, Erdem A, et al. Comparison of fracture resistance between cast, CAD/CAM milling, and direct metal laser sintering metal post systems. J Prosthodont Res 2016;60(1):23-28. DOI: 10.1016/ j.jpor.2015.08.001.

2. Barcellos RR, Correia DP, et al. Fracture resistance of endodontically treated teeth restored with intra-radicular post: the effects of post system and dentine thickness. J Biomech 2013;46(15): 2572-2577. DOI: 10.1016/j.jbiomech.2013.08.016.

3. Liu W, Qing H, et al. Internal adaptation of cobalt-chromium posts fabricated by selective laser melting technology. J Prosthet Dent 2019;121(3):455-460. DOI: 10.1016/j.prosdent.2018.03.017.

4. CastilloOyagüe R, Osorio $R$, et al. The effect of surface treatments on the microroughness of laser-sintered and vacuumcast base metal alloys for dental prosthetic frameworks. Microsc Res Tech 2012;75(9):1206-1212. DOI: 10.1002/jemt.22050.

5. Park JS, Lee JS, et al. Comparison of push-out bond strength of fiber-reinforced composite resin posts according to cement thickness. J Prosthet Dent 2017;118(3):372-378. DOI: 10.1016/ j.prosdent.2016.11.007.

6. Al-Assar RM, El-Ghani OS, et al. Effect of relining, cement type, and thermocycling on push-out bond strength of fiber reinforced posts. Future Dent J 2015;1(1):13-22. DOI: 10.1016/j.fdj.2015.11.001.

7. Stockton LW. Factors affecting retention of post systems: a literature review. J Prosthet Dent 1999;81(4):380-385. DOI: 10.1016/S00223913(99)80002-X.

8. Zicari F, De Munck J, et al. Factors affecting the cementpost interface. Dent Mater 2012;28(3):287-297. DOI: 10.1016/ j.dental.2011.11.003.

9. Vertucci FJ. Root canal anatomy of the human permanent teeth. Oral Surg, Oral Med, Oral Pathol 1984;58(5):589-599. DOI: 10.1016/00304220(84)90085-9.

10. Hudis $\mathrm{SI}$, Goldstein GR. Restoration of endodontically treated teeth: A review of the literature. J Prosthet Dent 1986;55(1):33-38. DOI: 10.1016/0022-3913(86)90068-5.

11. Morgano SM, Milot P. Clinical success of cast metal posts and cores. $J$ Prosthet Dent 1993;70(1):11-16. DOI: 10.1016/0022-3913(93)90030-R.

12. Tamac E, Toksavul S, et al. Clinical marginal and internal adaptation of CAD/CAM milling, laser sintering, and cast metal ceramic crowns. J Prosthet Dent 2014;112(4):909-913. DOI: 10.1016/ j.prosdent.2013.12.020.

13. Aleisa $\mathrm{K}, \mathrm{Al}-\mathrm{d}$ wairi $\mathrm{ZN}$, et al. Pull-out retentive strength of fiber posts cemented at different times in canals obturated with a eugenolbased sealer. J Prosthet Dent 2016;116(1):85-90. DOI: 10.1016/ j.prosdent.2015.12.010. 
14. Braga NM, Paulino SM, et al. Removal resistance of glass-fiber and metallic cast posts with different lengths. J Oral Sci 2006;48(1):15-20. DOI: $10.2334 /$ josnusd.48.15.

15. Oblak $C$, Jevnikar $P$, et al. Fracture resistance and reliability of new zirconia posts. J Prosthet Dent 2004;91(4):342-348. DOI: 10.1016/j. prosdent.2004.01.009.

16. Monticelli F, Osorio R, et al. Surface treatments for improving bond strength to prefabricated fiber posts: a literature review. Oper Dent 2008;33(3):346-355. DOI: 10.2341/07-86.

17. Almufleh BS, Aleisa KI, et al. Effect of surface treatment and type of cement on push-out bond strength of zirconium oxide posts. J Prosthet Dent 2014;112(4):957-963. DOI: 10.1016/j.prosdent.2014.04.022.

18. Younes AA, Kamel MS, et al. The effect of various fiber reinforced composite post surface treatments on its bond strength to root canal dentin. Tanta Dent J 2015;12:S15-S21. DOI: 10.1016/j.tdj.2015.05.011.

19. Miller $\mathrm{BH}$, Nakajima $\mathrm{H}$, et al. Bond strength between cements and metals used for endodontic posts. Dent Mater 1998;14(5): 312-320. DOI: 10.1016/S0109-5641(98)00044-X.

20. Silva GA, da LuzEC, et al. Influence of surface treatments on topography and bond strength of densely-sintered zirconium-oxide ceramic.
Ceram Int 2016;42(7):8136-8139. DOI: 10.1016/j.ceramint.2016 02.019 .

21. Lall S, Runu R. The effect of different cementation strategies on the pull-out bond strength of fiber post: an ex-vivo study. Int J Sci Rep 2016;2(4):68-73. DOI: 10.18203/issn.2454-2156.IntJSciRep20160995.

22. Wang VJ, Chen YM, et al. Effect of two fiber post types and two luting cement systems on regional post retention using the pushout test. Dent Mater 2008;24(3):372-377. DOI: 10.1016/j.dental. 2007.05.012.

23. Lencioni KA, Menani LR, et al. Tensile bond strength of cast commercially pure titanium dowel and cores cemented with three luting agents. J Prosthodont Res 2010;54(4):164-167. DOI: 10.1016/ j.jpor.2010.03.002.

24. Dastgurdi ME, Khabiri M, et al. Effect of post length and type of luting agent on the dislodging time of metallic prefabricated posts by using ultrasonic vibration. J Endod 2013;39(11):1423-1427. DOI: 10.1016/ j.joen.2013.07.005.

25. Quante K, Ludwig K, et al. Marginal and internal fit of metal-ceramic crowns fabricated with a new laser melting technology. Dent Mater 2008;24(10):1311-1315. DOI: 10.1016/j.dental.2008.02.011. 